\title{
Electrochemically derived functionalized graphene for bulk production of hydrogen peroxide
}

\author{
Munaiah Yeddala ${ }^{\ddagger}$, Pallavi Thakur ${ }^{\ddagger}$, Anugraha A and Tharangattu N. Narayanan ${ }^{\star}$
}

\author{
Full Research Paper \\ Address: \\ Tata Institute of Fundamental Research - Hyderabad, Sy. No. 36/P, \\ Gopanapally Village, Serilingampally Mandal, Hyderabad 500107, \\ India \\ Email: \\ Tharangattu N. Narayanan* - tnn@tifrh.res.in \\ * Corresponding author $\ddagger$ Equal contributors \\ Keywords: \\ electrochemical oxygen reduction; functionalized carbon; \\ functionalized graphene; $\mathrm{H}_{2} \mathrm{O}_{2}$ production; water treatment
}

\author{
Beilstein J. Nanotechnol. 2020, 11, 432-442. \\ doi:10.3762/bjnano.11.34 \\ Received: 28 October 2019 \\ Accepted: 13 February 2020 \\ Published: 09 March 2020 \\ This article is part of the thematic issue "Graphene and beyond". \\ Guest Editor: G. U. Kulkarni \\ (C) 2020 Yeddala et al.; licensee Beilstein-Institut. \\ License and terms: see end of document.
}

\begin{abstract}
On-site peroxide generation via electrochemical reduction is gaining tremendous attention due to its importance in many fields, including water treatment technologies. Oxidized graphitic carbon-based materials have been recently proposed as an alternative to metal-based catalysts in the electrochemical oxygen reduction reaction (ORR), and in this work we unravel the role of $\mathrm{C}=\mathrm{O}$ groups in graphene towards sustainable peroxide formation. We demonstrate a versatile single-step electrochemical exfoliation of graphite to graphene with a controllable degree of oxygen functionalities and thickness, leading to the formation of large quantities of functionalized graphene with tunable rate parameters, such as the rate constant and exchange current density. Higher oxygen-containing exfoliated graphene is known to undergo a two-electron reduction path in ORR having an efficiency of about $80 \pm 2 \%$ even at high overpotential. Bulk production of $\mathrm{H}_{2} \mathrm{O}_{2}$ via electrolysis was also demonstrated at low potential (0.358 $\mathrm{mV}$ vs RHE), yielding $\approx 34 \mathrm{mg} / \mathrm{L}$ peroxide with highly functionalized $(\approx 23$ atom $\%$ ) graphene and $\approx 16 \mathrm{~g} / \mathrm{L}$ with low functionalized $(\approx 13$ atom $\%)$ graphene, which is on par with the peroxide production using state-of-the-art precious-metal-based catalysts. Hence this method opens a new scheme for the single-step large-scale production of functionalized carbon-based catalysts (yield $\approx 45 \%$ by weight) that have varying functionalities and can deliver peroxide via the electrochemical ORR process.
\end{abstract}

\section{Introduction}

Hydrogen peroxide $\left(\mathrm{H}_{2} \mathrm{O}_{2}\right)$ is identified as one among the most important 100 chemicals in the world, and its applications extend from the pharmaceutical industry to water purification [1-3]. Today, a majority of the required $\mathrm{H}_{2} \mathrm{O}_{2}$ is produced through the complex and energy-intensive anthraquinone method [4], and although it is popular, it has drawbacks such as side reactions, which consume the catalyst leading to the regeneration and hydrogenation of the catalyst [4]. Alternative routes for peroxide generation include direct preparation of $\mathrm{H}_{2} \mathrm{O}_{2}$ from oxygen and hydrogen, oxidation of alcohols [5], photocatalysis [6], and electrochemical processes such as the electro-Fenton process [7], microbial electrosynthesis [8], and proton ex- 
change membrane (PEM) assisted synthesis [9]. Further, in situ generation of peroxide from dissolved oxygen via electrochemical ORR is identified as an effective route for water treatment technology, where economically viable, biologically friendly, sustainable catalysts are required [10-14].

Of the various routes, the direct synthesis of $\mathrm{H}_{2} \mathrm{O}_{2}$ through the reaction between $\mathrm{H}_{2}$ and $\mathrm{O}_{2}$ in the presence of a catalyst [15] is one of the possible routes having high yield, while the direct mixing of $\mathrm{H}_{2}$ and $\mathrm{O}_{2}$ can be explosive in nature [16], and hence requires a large quantity of another gas such as $\mathrm{N}_{2}$ and $\mathrm{CO}_{2}$ to dilute the reactant gases [17]. Electrochemical synthesis methods such as the PEM fuel cell reactor-based method can overcome this limitation; however, this method relies on expensive membranes to separate hydrogen and oxygen and to directly yield $\mathrm{H}_{2} \mathrm{O}_{2}$ from them [18]. Later, this method was modified by generating protons $\left(\mathrm{H}^{+}\right)$through water oxidation which eliminated the direct purging of $\mathrm{H}_{2}$ gas [9]. The major roadblock in this method is the development of a sustainable electrocatalyst for the selective reduction of oxygen to $\mathrm{H}_{2} \mathrm{O}_{2}$ [19-23]. Today, most electrochemical $\mathrm{H}_{2} \mathrm{O}_{2}$ production methods rely on precious-metal-based materials or transition metal and/or metal oxides, and hence their economic viability for the future technologies is highly questionable [10,24-27]. Hence new metal-free electrode materials for $\mathrm{H}_{2} \mathrm{O}_{2}$ generation are highly sought after for future technologies.

Recently, carbon-based catalysts have emerged as an alternate material for existing metal-based technologies [28,29]. For example, carbon nanotubes (CNTs) have been well studied for their catalytic activity, although conflicting reports exist due to the presence of unavoidable metallic impurities present [30-33]. With the emergence of graphene, heteroatom doping in $\mathrm{sp}^{2}$ graphitic structures is found to be an engineering pathway for altering the inert catalytic activity of planar honeycomb lattices of graphene and its derivatives [34,35]. It has been found that certain heteroatoms doped into graphene can even outperform the benchmark catalysts such as platinum $(\mathrm{Pt} / \mathrm{C})$ in their longrun alkaline ORR process where the extended stability in electrochemical processes is one of the crucial issues with $\mathrm{Pt} / \mathrm{C}$ [36]. In all of these doped systems, carbon atoms near to the defect centers are found as catalytically active centers [37] Recently, an ultra-small amount of selenium (Se) edge functionalized graphene (reduced graphene oxide ( $\mathrm{rGO})$ ) was found to undergo a direct four-electron path ORR process in alkaline medium, where rGO undergoes a two-electron path peroxide route ORR [35]. In this process, Se acts as a single atom site catalyst. In a nutshell, depending on the nature of the dopant and its position in the host lattice, it has been well reported that one can engineer the electrochemical activity of nanographitic systems and the catalytic reaction pathways [31,38-40].
Very recently, oxidized graphitic structures were identified for their efficacy towards the alkaline ORR process leading to selective peroxide production. In a recently reported theoretical study by Cui et al., the carbon atoms near the oxygen functionalities are used for their ORR efficacy via a two-electron pathway [37]. It was further experimentally shown that carbon materials such as CNTs, graphene, etc. can be oxidized via chemical treatment, and these oxidized forms of $\mathrm{sp}^{2}-\mathrm{sp}^{3}$ carbon systems prefer peroxide formation in alkaline ORR process [25]. Such studies are supported by reports from other groups, where McCloskey et al. showed that $\mathrm{sp}^{2}$-hybridized carbon near-ring ether defects along sheet edges are the most active sites for peroxide production in rGO [3]. They also showed that the performance of these rGO-based catalysts in alkaline conditions under low overpotential outperform the existing state-ofthe-art catalysts. However, a large extent of oxidation may hamper the charge transfer properties of functionalized graphene (graphene oxide (GO) or other functional derivatives of graphene) [41]. Hence the single-step method for the production of large scale, controllably functionalized graphene is of high demand, and in this work, we demonstrate such a method to control the extent of oxidation. Further, although it was proposed that $\mathrm{C}=\mathrm{O}$ (quinone) functional groups are the major candidates in deciding the peroxide route $\mathrm{O}_{2}$ reduction, here we provide experimental evidence for tuning the quinone groups in graphene and its correlation to the peroxide production.

In one of our previous works, different halogenated graphene materials were developed via a single-step electrochemical exfoliation (EE) method [42]. It was found that such a method can produce graphene with varying degrees of oxygen functionalities [43]. Here we explore the possibility of functional groups to control graphene toward the electrochemical production of $\mathrm{H}_{2} \mathrm{O}_{2}$ in alkaline medium, and the amount of peroxide generated is quantified using a spectroscopic technique. A large amount of $\mathrm{H}_{2} \mathrm{O}_{2}$ is found to be formed via such simple modification of the exfoliation parameters, and the details are discussed in this article.

\section{Results and Discussion}

The detailed physical characterization of electrochemically exfoliated graphene (EEG) was given in our recent report, where the variation in the oxygen functionalities, amount of fluorine content in exfoliated graphene, etc. were shown [43]. As discussed previously, the surface oxygen functional groups are crucial for the reduction of molecular oxygen to $\mathrm{H}_{2} \mathrm{O}_{2}$ and hence high-resolution $\mathrm{O} 1 \mathrm{~s}$ X-ray photoelectron spectroscopy (XPS) was carried out. The O 1s peaks of different EEG samples are shown in Figure 1a. It can be seen that the intensity of the $\mathrm{O} 1 \mathrm{~s}$ peak decreases from G-M1 to G-M4 (where G refers to graphene and M1, M2, M3, and M4 refer to the respective 

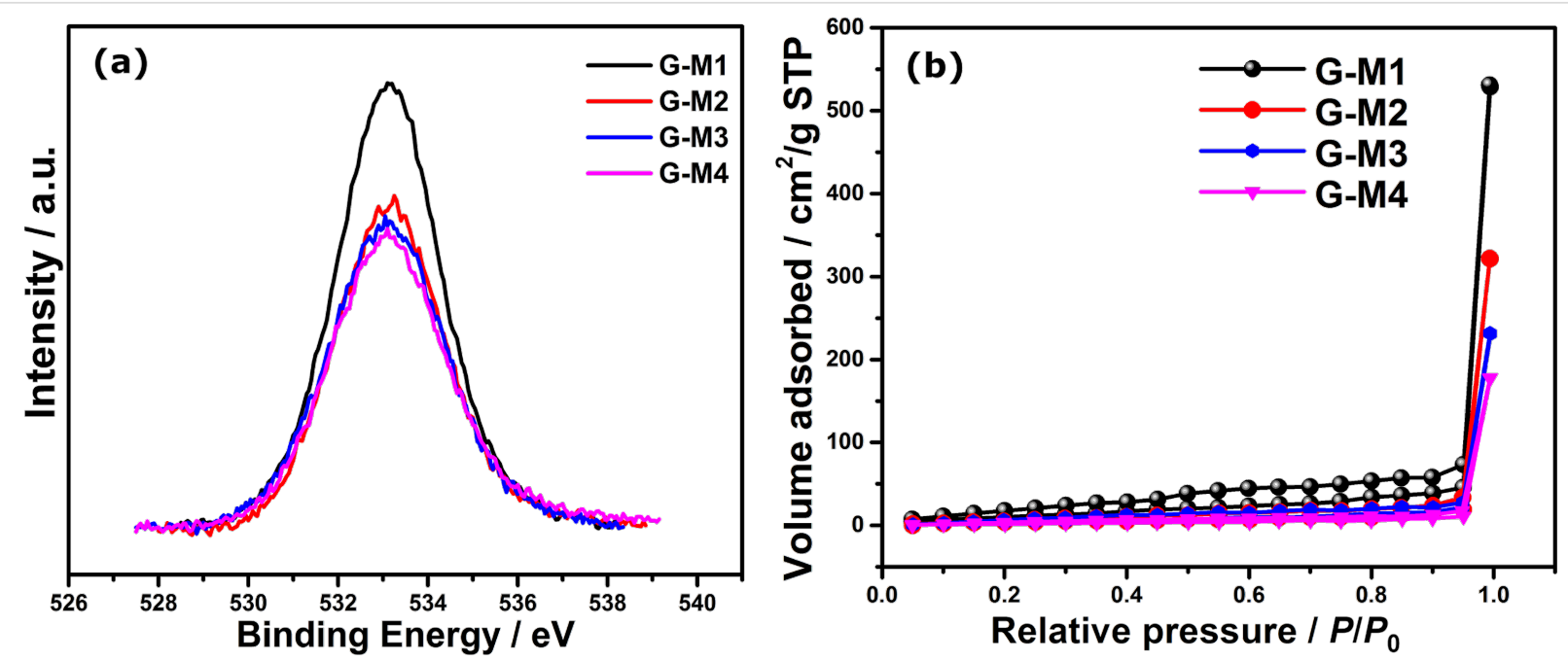

Figure 1: (a) High resolution O 1s XPS spectra of different EEG samples. (b) BET isotherms of different EEG samples.

molarity of the electrolyte used for the exfoliation), and the elemental composition calculated from the survey spectrum of the materials revealed that the degree of oxygen functionalization varies from $\approx 21$ to $\approx 10$ atom $\%$ from G-M1 to G-M4 (as inferred from the XPS survey spectrum as well as the high-resolution $\mathrm{C} 1 \mathrm{~s}$ and $\mathrm{O} 1 \mathrm{~s}$ XPS spectra (Supporting Information File 1, Figure S1a)) [43]. The O 1s spectrum can be deconvoluted into two distinct peaks (as shown in Figure S2) centered at $532.2 \mathrm{eV}$ and $533.4 \mathrm{eV}$, corresponding to alcoholic $(\mathrm{C}-\mathrm{OH}) /$ ether type of oxygen in ester functional groups and carbonyl $(\mathrm{C}=\mathrm{O}$ in $-\mathrm{COOH})$ functional groups, respectively $[42,44]$. Interestingly, irrespective of the degree of functionalization (oxygen content), carbonyl groups are found to be the major component in all the EEG samples. This correlates with the Fourier-transform infrared spectroscopy (FTIR) based analysis (Figure S1b), which also shows the presence of covalent $\mathrm{C}-\mathrm{F}$ functional groups in all the samples. The samples also contain fluorine as one of the dopants with a content varying from 2.3 to 3.9 atom \%. However, previous studies showed that the fluorine-doped graphene systems follow a direct four-electron ORR path [45-48], whereas some of the other fluorine-doped carbon prefers the $\mathrm{H}_{2} \mathrm{O}_{2}$ path during the ORR [49,50]. Along with the degree of functionalization, the surface area of the material can also influence the catalytic property of the materials since these EEG samples are derived from bulk graphite using a single-step exfoliation in different electrolytes. The BET isotherms of the EEG samples are shown in Figure 1b. The shape of the nitrogen adsorption and desorption curves displays a typical type III behavior, which corresponds to that of a layered material $[42,51]$. The surface area varies from $46 \pm 2 \mathrm{~m}^{2} / \mathrm{g}$ (G-M1) to $11 \pm 2 \mathrm{~m}^{2} / \mathrm{g}$ (G-M4). The change in the surface area can be attributed to the rate of exfoliation of the graphite rod which in turn depends upon the availability of fluoride and hydroxide ions at the anode (i.e., the higher the hydroxide ions the faster the exfoliation), which is in line with our recent report [43].

As described earlier, transmission electron microscopy (TEM) images of EEG samples indicate that the average lateral size is about 3-5 $\mu \mathrm{m}$ (more images in Supporting Information File 1) and scanning electron microscopy (SEM) images indicate the formation of randomly oriented exfoliated graphene nanosheets [43]. However, the TEM images show that the thickness of the graphene increases from G-M1 to G-M4, where the G-M4 is found to block the electron beam despite its layered nature (Supporting Information File 1, Figure S2). Here the thickness variation is confirmed using atomic force microscopy (AFM), and the results are given in Figure S3. This indicates that with an increase in the concentration of the electrolyte, the thickness is increased from $40 \mathrm{~nm}$ to $140 \mathrm{~nm}$ (Figure S3), which corresponds with the TEM analysis [43] and BET-based surface area data. Hence from the TEM, BET, and AFM analysis, it can be concluded that the electrolyte concentration is important for the electrochemical exfoliation assisted synthesis of ultrathin graphene layers, and the electrolyte concentration also determines the extent of functionalization of graphene.

The presence of the $\mathrm{C}=\mathrm{O}$ groups is further confirmed by cyclic voltammetry $(\mathrm{CV})$ measurements in alkaline and acidic electrolyte. The CV profiles of the EEG samples (EEG-modified glassy carbon electrode (GCE) as the working electrode in a three-electrode set up) in the acidic and alkaline medium between -0.2 to $1.2 \mathrm{~V}$ vs RHE at $100 \mathrm{mV} / \mathrm{s}$ scan rate are shown in Figure 2. Two distinct features observed in the $\mathrm{CV}$ profiles are: the difference in the area under the curve of the different EEG samples, which indicates the difference in the surface area of the electrodes; and secondly, the Faradaic redox peaks in acidic 

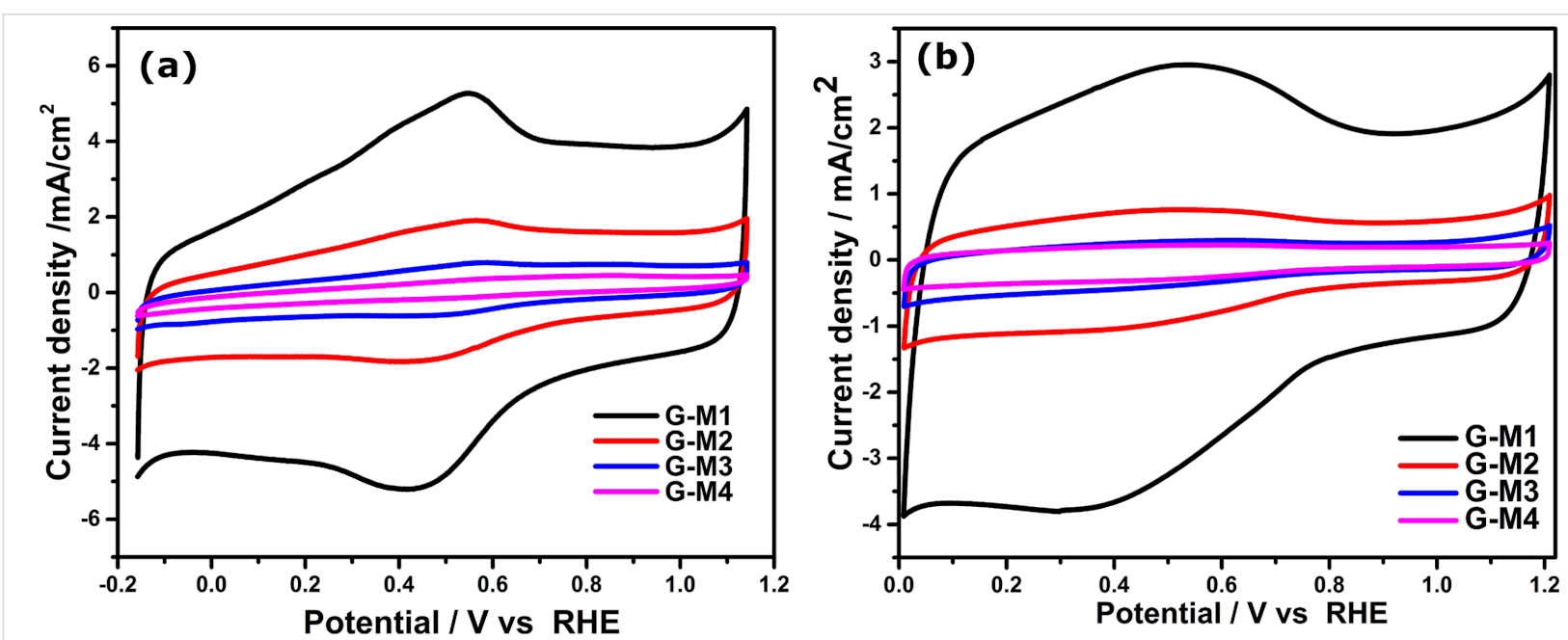

Figure 2: The $\mathrm{CV}$ profiles of different $\mathrm{EEG}$ samples in (a) acidic $\left(0.5 \mathrm{M} \mathrm{H}_{2} \mathrm{SO}_{4}\right)$ and (b) alkaline $(0.1 \mathrm{M} \mathrm{KOH})$ electrolyte at $100 \mathrm{mV} / \mathrm{s} \mathrm{scan}$ rate. The $\mathrm{CV}$ with low scan rate $(5 \mathrm{mV} / \mathrm{s})$ is shown in Supporting Information File 1, Figure S4a. The current densities are calculated using the geometrical area.

CV curves, which is nearly absent under alkaline conditions. Under both conditions (alkaline and acidic), G-M1 shows the highest surface area and G-M4 showed the lowest. This systematic variation in the electrochemical surface area corresponds with the BET analysis.

As mentioned, the $\mathrm{CV}$ profiles in the acidic medium show redox peaks at $\approx 0.5 \mathrm{~V}\left(0.5 \mathrm{M} \mathrm{H}_{2} \mathrm{SO}_{4}\right)$, which corresponds to the redox reaction of oxygen functional groups such as quinone to hydroquinone, as per the following equation [52-54]:

$$
\mathrm{Q}+2 \mathrm{H}^{+} \leftrightarrow \mathrm{QH}_{2}
$$

Interestingly, the intensity of the peak increases with the degree of functionalization, which further supports the assumption that the redox peak at $0.5 \mathrm{~V}$ is due to functionalization. These results are in good agreement with XPS data, as discussed previously. These redox peaks are not observed (only broad peaks) in alkaline medium (Figure $2 b$ ) under identical conditions due to the lack of the supply of protons (in acidic media, the conversion is $2 \mathrm{H}^{+}, 2 \mathrm{e}^{-}$reduction while in alkaline media it is only $2 \mathrm{e}^{-}$reduction where $\mathrm{Q}^{2-}$ stabilized by water molecules and all species $\mathrm{Q}^{2-}, \mathrm{QH}^{-}, \mathrm{QH}^{2-}$ are present in equilibrium). This indicates the presence of $\mathrm{C}=\mathrm{O}$ groups and their role in electrochemical processes.

The ORR activity of different EEG samples is estimated using a conventional three-electrode system. The CV profiles of EEGmodified GCE in $0.1 \mathrm{M} \mathrm{KOH}$ electrolyte saturated with $\mathrm{N}_{2}$ and $\mathrm{O}_{2}$ gas are displayed in Figure 3. The electrodes exhibit capacitive (double layer) behavior in $\mathrm{N}_{2}$-saturated electrolyte, while a sharp reduction peak corresponding to oxygen reduction in
$\mathrm{O}_{2}$-saturated electrolyte is shown in all the cases. The intensity of the peak (peak current density) corresponds to the ORR process and varies with the degree of oxygen functionalities (from G-M1 to G-M4), which reveals the effect of the degree of functionalization in ORR. The CV profiles plotted using the current densities calculated using the electrochemical surface area also shown similar trends, as shown in Supporting Information File 1, Figure S5 (the detailed procedure to calculate electrochemical surface area is given in the Supporting Information File 1, see Figure S6). To summarize, the G-M1 sample showed the highest reduction current under the same experimental conditions whereas G-M4 showed the lowest current with the rest of the samples in between these two samples.

To understand the ORR reaction pathway, rotating ring and disk electrode (RRDE)-based hydrodynamic voltammetry is conducted. Figure 4a shows ORR linear sweep voltammetry (LSV) scans of different EEG samples on GCE disk (4 mm diameter) and the $\mathrm{H}_{2} \mathrm{O}_{2}$ oxidation over the platinum ring (potential kept at $1.5 \mathrm{~V}$ vs RHE) at $10 \mathrm{mV} / \mathrm{s}$ scan rate at 1600 rotation per minute (rpm) for the electrode. The experiments are also carried out at different rotation speeds, and the data is given in Supporting Information File 1, Figure S7. The electrochemical parameters derived from these experiments (at $0.358 \mathrm{~V}$ vs RHE) are shown in Table 1. As shown in the Figure 4, the current density and onset potential of the reaction vary with the degree of (oxygen) functionalization. A benchmark $\mathrm{Pt} / \mathrm{C}$ catalyst performance is also shown for comparison.

The onset potential of ORR is found to become more favorable with a high degree of functionalization, reaching $860 \mathrm{mV}$ for the G-M1 electrode and $770 \mathrm{mV}$ for the G-M4 sample. The onset potential and current density of G-M2 and G-M3 are 

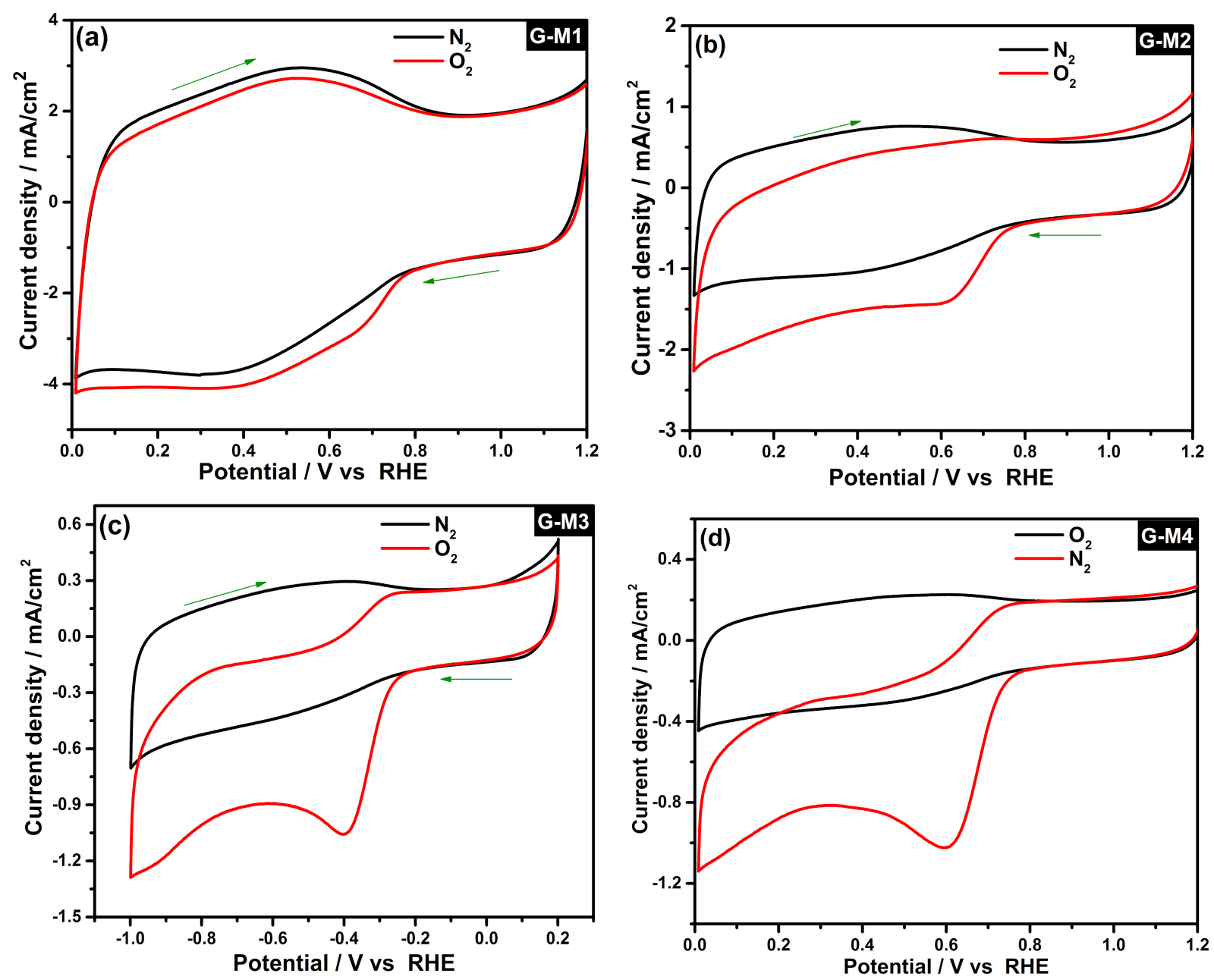

Figure 3: The $\mathrm{CV}$ profiles of different electrodes in $0.1 \mathrm{M} \mathrm{KOH}$ electrolyte saturated with $\mathrm{N}_{2}$ and $\mathrm{O}_{2}$. The current density is calculated using the geometrical surface area.

found to be between those of G-M1 and G-M4. Interestingly, the difference in fluorine content (which is nominal) did not affect the onset potential of the ring current. The shape of the LSV scans shows a two-step in reduction, which is due to the reduction of oxygen to $\mathrm{H}_{2} \mathrm{O}_{2}$ at lower overpotential and its further reduction to $\mathrm{H}_{2} \mathrm{O}$ at higher potentials [44]. This suggests that the ORR proceeds through a two-electron reduction path in EEG samples while the sharp Faradaic current enhancement followed by a plateau in $\mathrm{Pt} / \mathrm{C}$ shows that it is a one-step reduction process.

The quantity of $\mathrm{H}_{2} \mathrm{O}_{2}$ produced is analyzed using a platinum ring electrode at $1.5 \mathrm{~V}$ vs RHE. The ring current is higher (0.067 mA) for highly functionalized graphene and less (0.028 mA) for less functionalized (G-M4) graphene, which displays higher peroxide formation in G-M1. Hence G-M1 shows higher $\mathrm{O}_{2}$ reduction current and higher peroxide oxidation than the others because the oxygen functionalities possess selective activity towards ORR, which is in line with the other recent reports [37]. The number of electrons transferred per oxygen molecule and percentage $(\%)$ of $\mathrm{H}_{2} \mathrm{O}_{2}$ produced during ORR are calculated (using the details given in Supporting Information File 1), and the data are shown in Figure $4 b$ and $4 c$, respectively.

Table 1 gives the kinetic parameters calculated from Figure $4 \mathrm{a}$ (LSV of ORR on RRDE) at $0.358 \mathrm{~V}$ vs RHE. As shown in the table, all the EEG samples, irrespective the degree of functionalization, show the number of electrons transferred as $\approx 2.4$ electrons per oxygen and yield $\approx 80 \pm 2 \% \mathrm{H}_{2} \mathrm{O}_{2}$ generation. Figure $4 \mathrm{c}$ shows the number of electrons transferred over a potential range from 0.608 to $0.108 \mathrm{~V}$ vs RHE. Interestingly, the ORR follows the peroxide reduction path (about $2.2 \pm 0.1$ electron per oxygen molecule at $0.4 \mathrm{~V}$ vs RHE) at lower overvoltage, and the slight increase can be observed in the number of electrons transferred at higher overpotential. The 

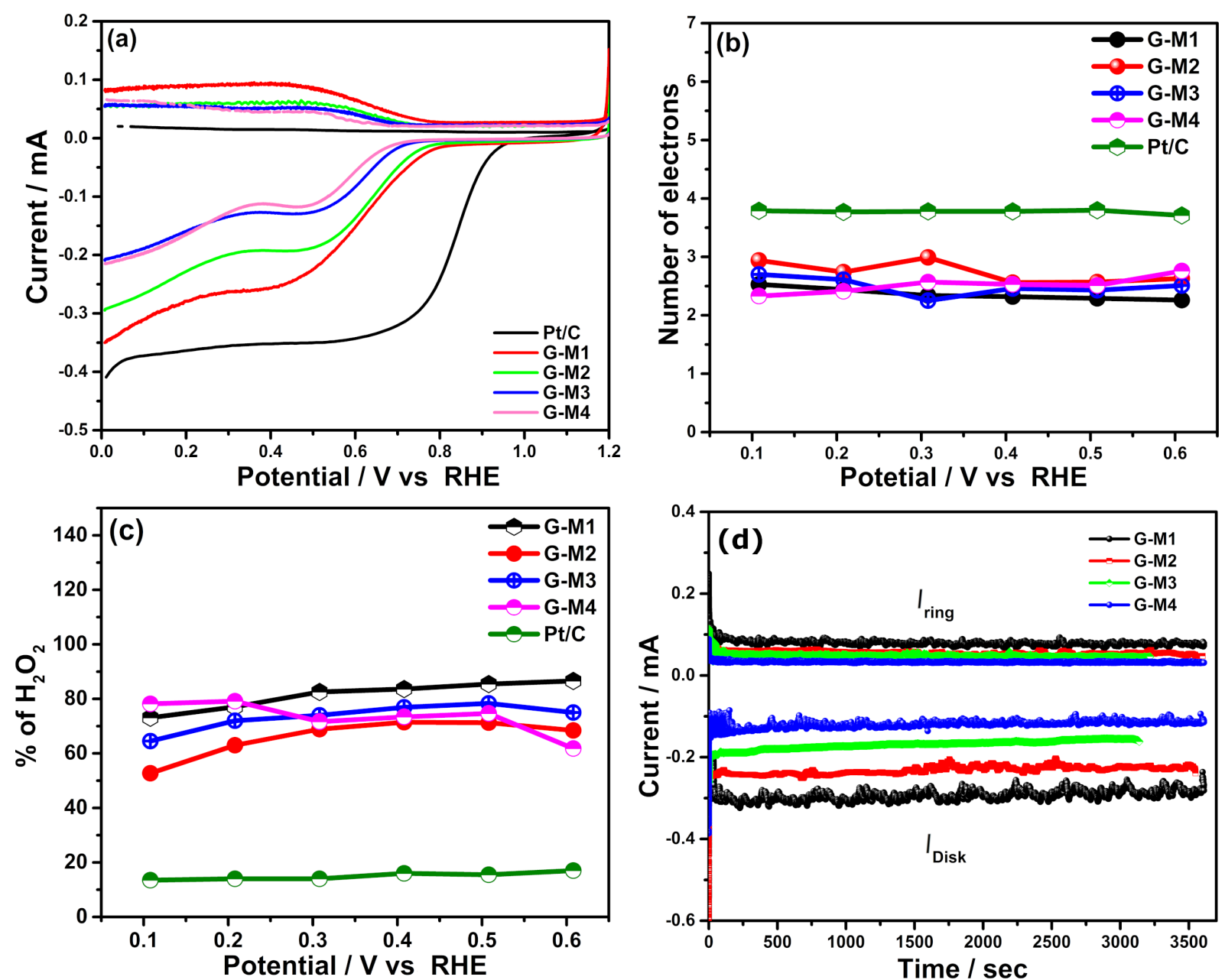

Figure 4: (a) LSV scans of $\mathrm{O}_{2}$ reduction and $\mathrm{H}_{2} \mathrm{O}_{2}\left(\mathrm{HO}_{2}^{-}\right)$oxidation on different EEG-modified RRDE samples. (b) The number of electrons transferred during ORR per $\mathrm{O}_{2}$ molecule and (c) the percentage (\%) of formed $\mathrm{H}_{2} \mathrm{O}_{2}$ (calculated from Figure 4a) is shown. (d) Chronoamperograms of $\mathrm{O}_{2}$ reduction and $\mathrm{H}_{2} \mathrm{O}_{2}$ oxidation processes at $0.358 \mathrm{~V}$ and $1.5 \mathrm{~V}$ vs $\mathrm{RHE}$ on different electrodes.

Table 1: The RRDE experiment electrochemical parameters obtained at $0.358 \mathrm{~V}$ (vs RHE, from Figure 4a).

\begin{tabular}{llllll} 
Active materials & Disk current $(\mathrm{mA})$ & Ring current $(\mathrm{mA})$ & Onset potential $(\mathrm{V})$ & Number of electrons $(n)$ & $\% \mathrm{H}_{2} \mathrm{O}_{2}$ at $0.358 \mathrm{~V}$ \\
\hline G-M1 & 0.24 & 0.067 & 0.86 & 2.35 & 82.07 \\
G-M2 & 0.18 & 0.046 & 0.84 & 2.41 & 79.09 \\
G-M3 & 0.12 & 0.031 & 0.81 & 2.43 & 78.43 \\
G-M4 & 0.11 & 0.028 & 0.77 & 2.40 & 80.01 \\
Pt/C & 0.32 & 0.015 & 1.01 & 3.65 & 17
\end{tabular}

increase in the number of electrons can be attributed to fluorine functional groups attached to graphene, which can undergo a direct 4-electron path at higher overpotential, as reported previously $[47,55]$. Highly fluorinated EEG (G-M2) shows about three electrons per oxygen at higher overpotential $(0.3008$ to $0.108 \mathrm{~V})$. However, it is found that the fluorine content can be reduced by reducing the concentration of the electrolyte, which further improves the selective production of $\mathrm{H}_{2} \mathrm{O}_{2}$ even at relatively higher overpotential.
In order to test the stability of these catalysts, chronoamperometry experiments were conducted using RRD electrodes where the disk current was kept at $0.358 \mathrm{~V}$ vs RHE and the ring potential was kept at $1.5 \mathrm{~V}$ vs RHE. Figure $4 \mathrm{~d}$ depicts the chronoamperograms of the ORR at the disk and $\mathrm{H}_{2} \mathrm{O}_{2}$ oxidation at the ring electrode for $1 \mathrm{~h}$ at $1600 \mathrm{rpm}$, which shows reasonable stability in the current over time (both electrodes). Furthermore, the variation in the current at the ring and disk for different EEG samples follows the same trend as that found in the LSV 
scans (Figure 4a). The stability of the EEG-based catalysts is also tested by repeated cycling of LSV at $1600 \mathrm{rpm}$ for 1000 cycles (at $100 \mathrm{mV} \cdot \mathrm{s}^{-1}$ ). The LSV scans of ORR before and after 1000 cycles are given in Supporting Information File 1, Figure S8 and the results show that all the EEG samples, irrespective of the degree of functionalization, display very little degradation in performance. This indicates that the functionalized EEG samples are stable electrocatalysts for electrochemical $\mathrm{H}_{2} \mathrm{O}_{2}$ production even under harsh alkaline conditions.

Hence it can be concluded that the presence of oxygen functional groups is a key factor in improving the ORR, and they undergo the redox process during the reaction in acidic medium (see Figure 2a). In order to test the durability of the materials in acidic medium, chronoamperometry studies were carried out in $0.5 \mathrm{M} \mathrm{H}_{2} \mathrm{SO}_{4}$ at $0.45 \mathrm{~V}$ vs RHE for $3 \mathrm{~h}$. The EEG samples were studied (before and after chronoamperometry) using Raman and FTIR spectroscopy along with the electrochemical performance in $0.1 \mathrm{M} \mathrm{KOH}$ solution, and the data is given in Figure 5. In Figure 5a, the Raman spectra of EEG before and after $3 \mathrm{~h}$ of chronoamperometry are shown, which show no appreciable change in either the peak position or peak intensity. This indicates that no additional defects are created during the experiment. The important Raman peaks are marked in the figure and the shoulder peak in " $G$ " is due to the additional single phonon intra-valley scattering process (named as D') which is due to the presence of defects. However, the FTIR spectrum (see Figure S4b) shows evidence for the formation of $\mathrm{OH}$ functional groups during the chronoamperometry, which is suggests that most of the $\mathrm{C}=\mathrm{O}$ functional groups are converted into $-\mathrm{C}-\mathrm{OH}$ during the reaction. To study the effect of the change in the functionalization on ORR, we recorded the $\mathrm{CV}$ of ORR in $0.1 \mathrm{M} \mathrm{KOH}$ solution before and after chronoamperometry. Such changes are found to have an insignificant effect on the performance of the material towards ORR (see Figure 5b).
To evaluate the EEG samples further, the kinetic parameters such as rate constant and exchange current density are calculated from the Tafel plot analysis (in $\mathrm{O}_{2}$-saturated electrolyte) and are shown in Figure 6. As expected, G-M1 shows a high exchange current $1.2 \times 10^{-5} \mathrm{~A}$, and G-M4 shows a low exchange current $7.4 \times 10^{-6} \mathrm{~A}$, which demonstrates that G-M1 is kinetically more favorable towards ORR than G-M4. The rate constant $(k)$ was calculated from the following equation [56], which is derived from the Butler-Volmer model [56]:

$$
i_{\mathrm{o}}=F A k^{0} C_{\mathrm{O}}^{*(1-\alpha)} C_{\mathrm{R}}^{*} \alpha
$$

where $i_{\mathrm{o}}$ is the exchange current density, $F$ is the Faraday constant $(96485 \mathrm{C}), C_{\mathrm{O}}^{*}$ is the concentration of the oxidant, $C_{\mathrm{R}}^{*}$ is the concentration of the reductant, $\alpha$ is the transfer coefficient, $A$ is the surface area of the electrode $\left(0.07 \mathrm{~cm}^{2}\right)$, and $k^{0}$ is the

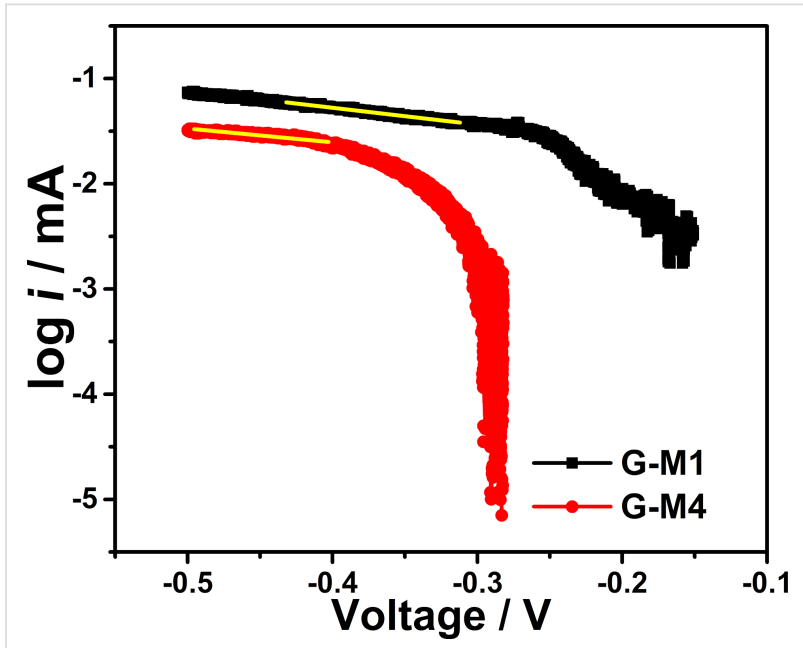

Figure 6: Tafel plots of ORR over EEG-modified electrodes in $0.1 \mathrm{M} \mathrm{KOH} \mathrm{O}_{2}$-saturated electrolyte.
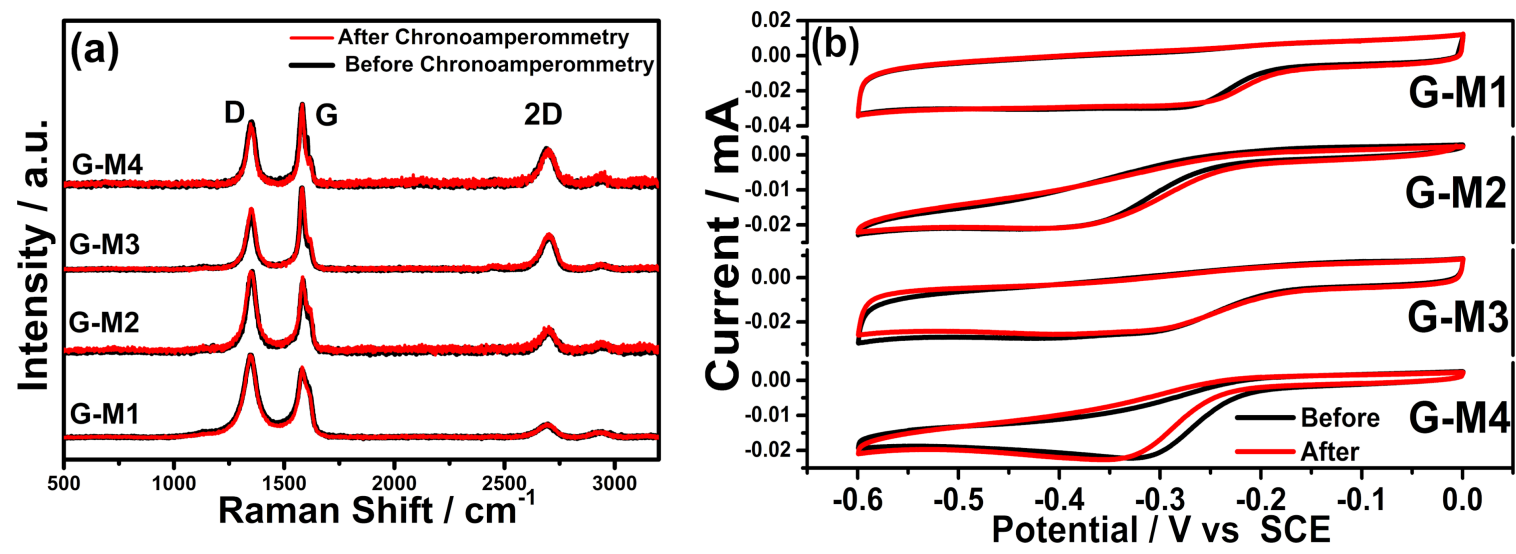

Figure 5: (a) Raman spectra of EEG samples before and after $3 \mathrm{~h}$ of chronoamperometry in $0.5 \mathrm{M} \mathrm{H}_{2} \mathrm{SO}_{4}$ solution at $0.45 \mathrm{~V}$ vs $\mathrm{RHE}$. (b) ORR in $0.1 \mathrm{M} \mathrm{KOH}$ solution before and after chronoamperometry. 
heterogeneous rate constant. In this case, we considered $C_{\mathrm{O}}=$ $C_{\mathrm{R}}=C$, where $C$ is the concentration of the dissolved oxygen which is $1.26 \times 10^{-6} \mathrm{~mol} \cdot \mathrm{cm}^{-3}$ [57,58]. The rate constant value calculated from the above equation is $1.39 \times 10^{-3} \mathrm{~cm} \cdot \mathrm{s}^{-1}$ for G-M1 and $8.52 \times 10^{-4} \mathrm{~cm} \cdot \mathrm{s}^{-1}$ for G-M4 which follow the trend observed in exchange current density. Both $i_{\mathrm{o}}$ and $k^{0}$ emphasize the importance of the quantity of functional groups in ORR.

Large-scale production of peroxide using these EEG samples are conducted using bulk electrolysis. EEG-coated and uncoated graphite paper was employed for the electrochemical production of $\mathrm{H}_{2} \mathrm{O}_{2}$. The $\mathrm{H}_{2} \mathrm{O}_{2}$ produced through ORR is also quantified using a $\mathrm{Ce}\left(\mathrm{SO}_{4}\right)_{2}$ solution assisted $\mathrm{UV}$-visible absorbance based analysis, where the details and calibration are given in Supporting Information File 1. Figure 7a shows chronoamperograms of ORR on EEG-coated graphite papers at $0.358 \mathrm{~V}$ vs RHE in $0.1 \mathrm{M} \mathrm{KOH}$ electrolyte for $3 \mathrm{~h}$. G-M1 shows the highest current where the current subsequently reduced from sample G-M1 to G-M4. The amount of $\mathrm{H}_{2} \mathrm{O}_{2}$ produced is calculated as $34.5,31.6,23.4$, and $16.4 \mathrm{mg} / \mathrm{L}$ for G-M1, G-M2, G-M3, and G-M4, respectively. The high quantity of $\mathrm{H}_{2} \mathrm{O}_{2}$ production in G-M1 can be attributed to its high degree of oxygen functional groups, particularly due to $\mathrm{C}=\mathrm{O}$. The amount of peroxide formed by this method is found to be higher or on par with recent reports [3]. This opens an efficient pathway for the single-step large-scale production of peroxidegenerating carbon-based ORR catalysts.

The weight of the anode (graphite electrode) used for the electrochemical exfoliation was $\approx 0.374 \mathrm{~g}$ and the $1-2 \mathrm{~h}$ of exfoliation resulted in the complete consumption of graphite, deliv- ering $\approx 0.180 \pm 0.005 \mathrm{~g}$ of exfoliated functionalized graphene. Hence the average yield of this process was found to be $\approx 45 \%$.

Hence such chemically modified graphene powders, which are proven to be dispersible in a variety of organic solvents [59], offer alternate possibilities towards existing metal-based peroxide generation technologies. Controlling the electronic properties via the thermal reduction method can further tune the charge transfer properties of such functionalized graphene powders [60], opening a plethora of opportunities in this field.

\section{Conclusion}

An efficient single-step method (without any post-treatment) has been developed for the high-yield synthesis of carbon-based peroxide, generating ORR catalysts having varying functionalities. The role of quinone-containing functional groups in graphene towards the electrochemical ORR process is unraveled, and the higher $\mathrm{C}=\mathrm{O}$ content results in a large amount of $\mathrm{H}_{2} \mathrm{O}_{2}$ production at a high rate. The other functionalities in graphene such as fluorine have a minimal role in lower potential reduction reactions while they become prominent at higher potentials, where they undergo a direct four-electron reduction of $\mathrm{O}_{2}$ to water. The concentration of the electrolyte was found to be related to the thickness of the formed exfoliated graphene and its functionalities, and the 1 M KF-based exfoliation resulted in ultrathin layers for the sample G-M1, which had a high amount of $\mathrm{C}=\mathrm{O}$ groups but fewer $\mathrm{C}-\mathrm{F}$ functionalities. These electrochemically exfoliated functionalized graphene samples are found to be highly stable in alkaline electrochemical conditions, whereby $3 \mathrm{~h}$ of ORR produced $\approx 34 \mathrm{mg} / \mathrm{L}$ of peroxide for an applied potential of $0.358 \mathrm{~V}$ vs RHE, indicating
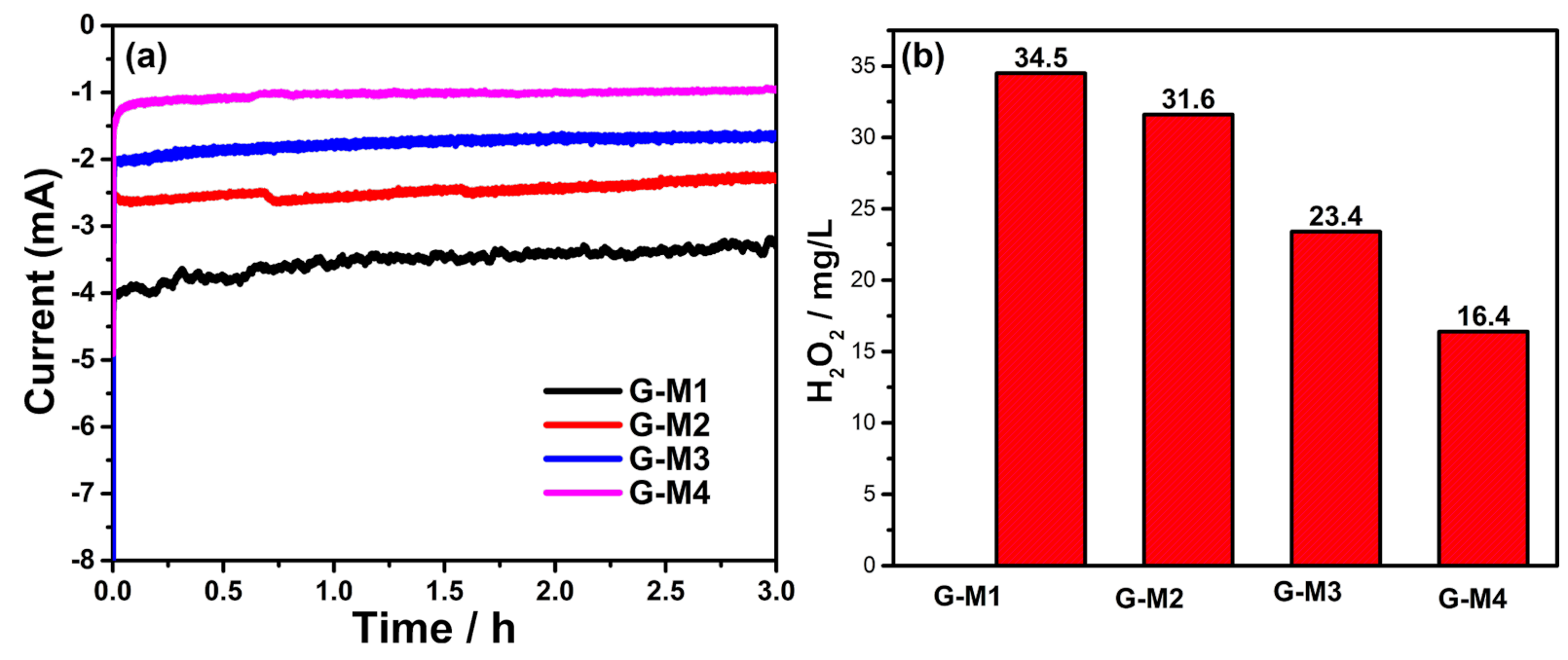

Figure 7: (a) Chronoamperogram of $\mathrm{O}_{2}$ reduction at $0.358 \mathrm{~V}$ on graphite paper modified with EEG. (b) The amount of $\mathrm{H}_{2} \mathrm{O}_{2}$ produced by each sample is shown in Figure $7 \mathrm{~b}$. 
a production on par or higher than the recently reported stateof-the-art catalysts [3].

\section{Experimental Materials}

Graphite rods of $3 \mathrm{~mm}$ diameter and $150 \mathrm{~mm}$ length with 99.999\% purity, sodium hydroxide (ACS grade), sulfuric acid, and hydrogen peroxide $(27 \% \mathrm{w} / \mathrm{v})$ were obtained from Alfa Aesar. Nafion solution ( $5 \% \mathrm{w} / \mathrm{w})$ was purchased from SigmaAldrich, and potassium fluoride (KF) and $\mathrm{Ce}\left(\mathrm{SO}_{4}\right)_{2}$ were obtained from Sisco research laboratories, India. All of the high purity chemicals were employed as-received without any further purification. Ultrahigh purity oxygen (99.999\%) was used for electrochemical reactions.

\section{Synthesis of electrochemically exfoliated graphene (EEG)}

EEG was synthesized via a method reported previously [42,43], where the degree of functionalization can be tuned by changing the concentration of the electrolyte (KF) from 1 to $4 \mathrm{M}$. In this process, two graphite rods were used as electrodes in $\mathrm{KF}$ aqueous electrolyte having different concentrations. A regulated DC power supply (Physitech electronics, model: PHY 8230) in galvanostatic mode $\left(0.2 \mathrm{~A} / \mathrm{cm}^{2}\right)$ was employed to carry out the electrochemical exfoliation. After the complete consumption of the graphite rod (anode), a black precipitate was collected from the electrolyte through centrifugation and subsequently washed with $1 \mathrm{M} \mathrm{H}_{2} \mathrm{SO}_{4}$ followed by deionized water until the solution becomes neutral $\mathrm{pH}$. The powder was dried at $60{ }^{\circ} \mathrm{C}$ for $12 \mathrm{~h}$ and used for further studies. The samples prepared in $1 \mathrm{M}, 2 \mathrm{M}, 3 \mathrm{M}$, and $4 \mathrm{M} \mathrm{KF}$ electrolytes were named as G-M1, G-M2, G-M3, and G-M4, respectively.

\section{Characterization}

As prepared EEG samples were characterized using a Renishaw Invia Raman spectrometer with a $532 \mathrm{~nm}$ laser as the excitation source. XPS (Thermo Scientific EASCA lab 2000) and FTIR spectroscopy were used to unravel the nature and degree of functionalization along with the change in morphology of these samples. The surface area of the samples was analyzed using Brunauer-Emmett-Teller (BET) adsorption isotherms from a Quantachrome Nova 1200e surface area analyzer. AFM was used to study the thickness of the exfoliated layers.

\section{Electrochemical experiments}

All of the electrochemical ORR experiments were carried out in a conventional three-electrode system with a catalyst ink modified GCE as a working electrode, $\mathrm{Hg} / \mathrm{Hg}_{2} \mathrm{Cl}_{2}$ and platinum foil (results were cross-checked with graphite rod counter electrode, too) used as a reference and counter electrodes, respectively. The electrochemical performance of the materials was analyzed using cyclic voltammetry (CV), linear sweep voltammetry (LSV), and rotating ring and disk electrode (RRDE) measurements. A BioLogic SP-300 instrument was used for these controlled experiments and an RRDE with a GC disk (4 mm diameter) and Pt ring ( $5 \mathrm{~mm}$ and $7 \mathrm{~mm}$ outer and inner diameters, respectively) electrode was employed for the RRDE-based experiments. The catalyst ink for the electrochemical characterization was prepared by dispersing $10 \mathrm{mg}$ of functionalized graphene in $375 \mu \mathrm{L}$ of the solvent mixture consisting of isopropyl alcohol (IPA, $275 \mu \mathrm{L})$, water $(50 \mu \mathrm{L})$, and $N, N$-dimethyl formamide (DMF, $50 \mu \mathrm{L}$ ). $3 \mu \mathrm{L}$ and $5 \mu \mathrm{L}$ of the above-prepared ink was drop cast over the well-polished GCE and RRDE (GCE disk having $4 \mathrm{~mm}$ diameter), respectively. All of the electrochemical experiments were carried out in $0.1 \mathrm{M} \mathrm{KOH}$ solution (for ORR process) and $0.5 \mathrm{M} \mathrm{H}_{2} \mathrm{SO}_{4}$ solution (for electrochemical surface area measurements). The $0.1 \mathrm{M} \mathrm{KOH}$ electrolyte was initially saturated with ultrahigh pure $\mathrm{N}_{2}$ followed by $\mathrm{O}_{2}$ gas before the respective analysis. The details of the calculation for the number of electrons transferred are given in Supporting Information File 1.

The quantification of the $\mathrm{H}_{2} \mathrm{O}_{2}$ produced was carried out using a UV-vis spectrometer [37,61]. A calibration curve was made using $1 \mathrm{mM} \mathrm{Ce}\left(\mathrm{SO}_{4}\right)_{2}(25 \mathrm{~mL})$ solution, $1 \% \mathrm{H}_{2} \mathrm{O}_{2}$ solution $\left(30 \% \mathrm{H}_{2} \mathrm{O}_{2}\right.$ solution was diluted to $1 \%$ ) and the details can be found in Supporting Information File 1 (Figure S9) [61]. Bulk electrolysis was conducted using the above-mentioned inks. In brief, $100 \mu \mathrm{L}$ of the above-prepared catalyst ink was drop cast over a $1 \mathrm{~cm}^{2}$ area of the Toray carbon paper having $100 \mathrm{~mm}$ length and dried at room temperature. These electrodes were used as working electrodes for bulk electrolysis wherein the electrochemical cell constitutes $100 \mathrm{~mL}$ of $\mathrm{O}_{2}$-saturated $0.1 \mathrm{M} \mathrm{KOH}$ electrolyte and a constant potential of $0.358 \mathrm{~V}$ vs RHE, applied for $3 \mathrm{~h}$. Subsequently, the sample ( $3 \mathrm{~mL}$ of electrolyte) was collected and used for the quantification of the $\mathrm{H}_{2} \mathrm{O}_{2}$. The details of the quantification are given in Supporting Information File 1.

\section{Supporting Information}

The supporting information includes additional TEM images, a detailed description of the quantification of $\mathrm{H}_{2} \mathrm{O}_{2}$, deconvoluted XPS spectra of O 1s, AFM analysis, FTIR spectra, ECSA calculations, and RRDE analysis for all EEG samples.

\section{Supporting Information File 1}

Additional experimental results and analysis.

[https://www.beilstein-journals.org/bjnano/content/ supplementary/2190-4286-11-34-S1.pdf] 


\section{Acknowledgements}

We thank Prof. Vijayamohanan K. Pillai, IISER Tirupati for his valuable suggestions which helped to improve the quality of the work.

\section{Funding}

The authors thank the Tata Institute of Fundamental Research Hyderabad for the financial support. The authors also acknowledge support from the Department of Atomic Energy, Government of India, under project no. 13/3(13)/2012/TIFR/R\&D-II/ VoI.IV/6768.

\section{ORCID ${ }^{\circledR}$ iDs}

Munaiah Yeddala - https://orcid.org/0000-0001-6241-7897 Tharangattu N. Narayanan - https://orcid.org/0000-0002-5201-7539

\section{References}

1. Pesterfield, L. J. Chem. Educ. 2009, 86, 1182. doi:10.1021/ed086p1182

2. Fukuzumi, S.; Yamada, Y.; Karlin, K. D. Electrochim. Acta 2012, 82, 493-511. doi:10.1016/j.electacta.2012.03.132

3. Kim, H. W.; Ross, M. B.; Kornienko, N.; Zhang, L.; Guo, J.; Yang, P.; McCloskey, B. D. Nat. Catal. 2018, 1, 282-290. doi:10.1038/s41929-018-0044-2

4. Campos-Martin, J. M.; Blanco-Brieva, G.; Fierro, J. L. G. Angew. Chem., Int. Ed. 2006, 45, 6962-6984. doi:10.1002/anie.200503779

5. Iwahama, T.; Sakaguchi, S.; Ishii, Y. Org. Process Res. Dev. 2000, 4, 94-97. doi:10.1021/op990082f

6. Zhang, J.; Chang, X.; Luo, Z.; Wang, T.; Gong, J. Chem. Commun. 2018, 54, 7026-7029. doi:10.1039/c8cc03303j

7. Oturan, N.; Oturan, M. A. Electro-Fenton Process: Background, New Developments, and Applications. Electrochemical Water and Wastewater Treatment; Elsevier: Amsterdam, Netherlands, 2018; pp 193-221. doi:10.1016/b978-0-12-813160-2.00008-0

8. Rabaey, K.; Rozendal, R. A. Nat. Rev. Microbiol. 2010, 8, 706-716. doi:10.1038/nrmicro2422

9. Yang, S.; Verdaguer-Casadevall, A.; Arnarson, L.; Silvioli, L.; Čolić, V.; Frydendal, R.; Rossmeisl, J.; Chorkendorff, I.; Stephens, I. E. L. ACS Catal. 2018, 8, 4064-4081. doi:10.1021/acscatal.8b00217

10. Viswanathan, V.; Hansen, H. A.; Nørskov, J. K. J. Phys. Chem. Lett. 2015, 6, 4224-4228. doi:10.1021/acs.jpclett.5b02178

11. Feng, Y.; Yang, L.; Liu, J.; Logan, B. E. Environ. Sci.: Water Res. Technol. 2016, 2, 800-831. doi:10.1039/c5ew00289c

12. Brillas, E.; Mur, E.; Sauleda, R.; Sànchez, L.; Peral, J.; Domènech, X.; Casado, J. Appl. Catal., B 1998, 16, 31-42. doi:10.1016/s0926-3373(97)00059-3

13. Matsue, T.; Fujihira, M.; Osa, T. J. Electrochem. Soc. 1981, 128, 2565-2569. doi:10.1149/1.2127292

14. Brillas, E.; Sauleda, R.; Casado, J. J. Electrochem. Soc. 1999, 146 , 4539-4543. doi:10.1149/1.1392671

15. Clerici, M. G.; Ingallina, P. Catal. Today 1998, 41, 351-364. doi:10.1016/s0920-5861(98)00025-x

16. Ranganathan, S.; Sieber, V. Catalysts 2018, 8, 379. doi:10.3390/catal8090379
17. Hâncu, D.; Beckman, E. J. Green Chem. 2001, 3, 80-86. doi:10.1039/b008515o

18. Otsuka, K.; Yamanaka, I. Electrochim. Acta 1990, 35, 319-322. doi:10.1016/0013-4686(90)87004-I

19. Jiang, Y.; Ni, P.; Chen, C.; Lu, Y.; Yang, P.; Kong, B.; Fisher, A.; Wang, X. Adv. Energy Mater. 2018, 8, 1801909. doi:10.1002/aenm.201801909

20. Yeddala, M.; Gorle, D. B.; Anbu kulandainathan, M.; Ragupathy, P.; Pillai, V. K. J. Colloid Interface Sci. 2019, 545, 71-81. doi:10.1016/j.jcis.2019.02.095

21. Rastogi, P. K.; Sahoo, K. R.; Thakur, P.; Sharma, R.; Bawari, S.; Podila, R.; Narayanan, T. N. Phys. Chem. Chem. Phys. 2019, 21, 3942-3953. doi:10.1039/c8cp06155f

22. Munaiah, Y.; Boopathi, S.; Senthil Kumar, S.; Ragupathy, P. Mater. Lett. 2019, 239, 184-191. doi:10.1016/j.matlet.2018.12.057

23. Park, J.; Nabae, Y.; Hayakawa, T.; Kakimoto, M.-a. ACS Catal. 2014, 4, 3749-3754. doi:10.1021/cs5008206

24. Yamanaka, I.; Ichihashi, R.; Iwasaki, T.; Nishimura, N.; Murayama, T.; Ueda, W.; Takenaka, S. Electrochim. Acta 2013, 108, 321-329. doi:10.1016/j.electacta.2013.06.072

25. Shi, X.; Siahrostami, S.; Li, G.-L.; Zhang, Y.; Chakthranont, P.; Studt, F.; Jaramillo, T. F.; Zheng, X.; Nørskov, J. K. Nat. Commun. 2017, 8, 701. doi:10.1038/s41467-017-00585-6

26. Campos, M.; Siriwatcharapiboon, W.; Potter, R. J.; Horswell, S. L. Catal. Today 2013, 202, 135-143. doi:10.1016/j.cattod.2012.05.015

27. Yamanaka, I.; Onizawa, T.; Suzuki, H.; Hanaizumi, N.; Nishimura, N.; Takenaka, S. J. Phys. Chem. C 2012, 116, 4572-4583. doi:10.1021/jp207679e

28. Chen, S.; Chen, Z.; Siahrostami, S.; Kim, T. R.; Nordlund, D.; Sokaras, D.; Nowak, S.; To, J. W. F.; Higgins, D.; Sinclair, R.; Nørskov, J. K.; Jaramillo, T. F.; Bao, Z. ACS Sustainable Chem. Eng. 2018, 6, 311-317. doi:10.1021/acssuschemeng.7b02517

29. Melchionna, M.; Fornasiero, P.; Prato, M. Adv. Mater. (Weinheim, Ger.) 2019, 31, 1802920. doi:10.1002/adma.201802920

30. Pal, S.; Narayanaru, S.; Kundu, B.; Sahoo, M.; Bawari, S.; Rao, D. K.; Nayak, S. K.; Pal, A. J.; Narayanan, T. N. J. Phys. Chem. C 2018, 122, 23385-23392. doi:10.1021/acs.jpcc.8b08933

31. Sun, T.; Zhang, G.; Xu, D.; Lian, X.; Li, H.; Chen, W.; Su, C. Mater. Today Energy 2019, 12, 215-238. doi:10.1016/j.mtener.2019.01.004

32. Munaiah, Y.; Dheenadayalan, S.; Ragupathy, P.; Pillai, V. K. ECS J. Solid State Sci. Technol. 2013, 2, M3182-M3186. doi:10.1149/2.024310jss

33. Munaiah, Y.; Suresh, S.; Dheenadayalan, S.; Pillai, V. K.; Ragupathy, P. J. Phys. Chem. C 2014, 118, 14795-14804. doi:10.1021/jp503287r

34. Vineesh, T. V.; Nazrulla, M. A.; Krishnamoorthy, S.; Narayanan, T. N.; Alwarappan, S. Appl. Mater. Today 2015, 1, 74-79. doi:10.1016/j.apmt.2015.09.002

35. Vineesh, T. V.; Kumar, M. P.; Takahashi, C.; Kalita, G.; Alwarappan, S.; Pattanayak, D. K.; Narayanan, T. N. Adv. Energy Mater. 2015, 5, 1500658. doi:10.1002/aenm.201500658

36. Kumar, M. P.; Raju, M. M.; Arunchander, A.; Selvaraj, S.; Kalita, G.; Narayanan, T. N.; Sahu, A. K.; Pattanayak, D. K. J. Electrochem. Soc. 2016, 163, F848-F855. doi:10.1149/2.0541608jes

37. Lu, Z.; Chen, G.; Siahrostami, S.; Chen, Z.; Liu, K.; Xie, J.; Liao, L.; Wu, T.; Lin, D.; Liu, Y.; Jaramillo, T. F.; Nørskov, J. K.; Cui, Y. Nat. Catal. 2018, 1, 156-162. doi:10.1038/s41929-017-0017-x

38. Kong, X.-K.; Chen, C.-L.; Chen, Q.-W. Chem. Soc. Rev. 2014, 43, 2841-2857. doi:10.1039/c3cs60401b 
39. Wu, J.; Ma, L.; Yadav, R. M.; Yang, Y.; Zhang, X.; Vajtai, R.; Lou, J.; Ajayan, P. M. ACS Appl. Mater. Interfaces 2015, 7, 14763-14769. doi:10.1021/acsami.5b02902

40. Zheng, B.; Wang, J.; Wang, F.-B.; Xia, X.-H. Electrochem. Commun. 2013, 28, 24-26. doi:10.1016/j.elecom.2012.11.037

41. Boopathi, S.; Narayanan, T. N.; Senthil Kumar, S. Nanoscale 2014, 6, 10140-10146. doi:10.1039/c4nr02563f

42. Munaiah, Y.; Ragupathy, P.; Pillai, V. K. J. Electrochem. Soc. 2016, 163, A2899-A2910. doi:10.1149/2.0321614jes

43. Yeddala, M.; Narayanan, T. N.; Pitchai, R.; Pillai, V. K. ChemistrySelect 2019, 4, 11385-11393. doi:10.1002/slct.201902114

44. Zhong, R.-S.; Qin, Y.-H.; Niu, D.-F.; Tian, J.-W.; Zhang, X.-S.; Zhou, X.-G.; Sun, S.-G.; Yuan, W.-K. J. Power Sources 2013, 225, 192-199. doi:10.1016/j.jpowsour.2012.10.043

45. Liu, A.; Li, W.; Jin, H.; Yu, X.; Bu, Y.; He, Y.; Huang, H.; Wang, S.; Wang, J. Electrochim. Acta 2015, 177, 36-42. doi:10.1016/j.electacta.2015.03.166

46. Kakaei, K.; Balavandi, A. J. Colloid Interface Sci. 2017, 490, 819-824. doi:10.1016/j.jcis.2016.12.011

47. Qiao, X.; Liao, S.; Wang, G.; Zheng, R.; Song, H.; Li, X. Carbon 2016, 99, 272-279. doi:10.1016/j.carbon.2015.12.034

48. Zhao, J.; Cabrera, C. R.; Xia, Z.; Chen, Z. Carbon 2016, 104, 56-63. doi:10.1016/j.carbon.2016.03.013

49. Zhao, K.; Su, Y.; Quan, X.; Liu, Y.; Chen, S.; Yu, H. J. Catal. 2018, 357, 118-126. doi:10.1016/j.jcat.2017.11.008

50. Sun, X.; Zhang, Y.; Song, P.; Pan, J.; Zhuang, L.; Xu, W.; Xing, W. ACS Catal. 2013, 3, 1726-1729. doi:10.1021/cs400374k

51. Deng, W.; Fang, Q.; Zhou, X.; Cao, H.; Liu, Z. RSC Adv. 2016, 6, 20843-20849. doi:10.1039/c5ra26088d

52. Zhang, H.-J.; Li, H.; Li, X.; Zhao, B.; Yang, J. Int. J. Hydrogen Energy 2014, 39, 16964-16975. doi:10.1016/j.jjhydene.2014.08.093

53. Tarasevich, M. R.; Bogdanovskaya, V. A.; Zagudaeva, N. M. J. Electroanal. Chem. Interfacial Electrochem. 1987, 223, 161-169. doi:10.1016/0022-0728(87)85257-9

54. Yi, Y.; Weinberg, G.; Prenzel, M.; Greiner, M.; Heumann, S.; Becker, S.; Schlögl, R. Catal. Today 2017, 295, 32-40. doi:10.1016/j.cattod.2017.07.013

55. Panomsuwan, G.; Saito, N.; Ishizaki, T. J. Mater. Chem. A 2015, 3 , 9972-9981. doi:10.1039/c5ta00244c

56. Bard, A. J.; Faulkner, L. R.; Leddy, J.; Zoski, C. G. Electrochemical methods: fundamentals and applications; Wiley: New York, 1980; Vol. 2.

57. Blizanac, B. B.; Ross, P. N.; Marković, N. M. J. Phys. Chem. B 2006, 110, 4735-4741. doi:10.1021/jp056050d

58. Min, X.; Chen, Y.; Kanan, M. W. Phys. Chem. Chem. Phys. 2014, 16, 13601-13604. doi:10.1039/c4cp01337a

59. Park, S.; An, J.; Jung, I.; Piner, R. D.; An, S. J.; Li, X.; Velamakanni, A.; Ruoff, R. S. Nano Lett. 2009, 9, 1593-1597. doi:10.1021/n1803798y

60. Ganguly, A.; Sharma, S.; Papakonstantinou, P.; Hamilton, J. J. Phys. Chem. C 2011, 115, 17009-17019. doi:10.1021/jp203741y

61. Greenhaus, H. L.; Feibush, A. M.; Gordon, L. Anal. Chem. (Washington, DC, U. S.) 1957, 29, 1531-1534. doi:10.1021/ac60130a045

\section{License and Terms}

This is an Open Access article under the terms of the Creative Commons Attribution License (https://creativecommons.org/licenses/by/4.0). Please note that the reuse, redistribution and reproduction in particular requires that the authors and source are credited.

The license is subject to the Beilstein Journal of Nanotechnology terms and conditions: (https://www.beilstein-journals.org/bjnano)

The definitive version of this article is the electronic one which can be found at:

doi:10.3762/bjnano.11.34 